\title{
THE EFFECTS OF ACID-BASE BALANCE ON THE DIURESIS PRODUCED BY ORGANIC AND INORGANIC MERCURIALS ${ }^{1}$
}

\author{
By ROBERT I. LEVY,² I. M. WEINER, ${ }^{3}$ AND GILBERT H. MUDGE With THE TECH NICAL \\ ASSISTANCE OF FLORENCE RISSER, CHARLOTTE BILLS, AND \\ SALLY RENSHAW
}

\author{
(From the Department of Pharmacology and Experimental Therapeutics, The Johns Hopkins \\ University School of Medicine, Baltimore, Md.)
}

(Submitted for publication January 29, 1958; accepted March 20, 1958)

Changes in acid-base metabolism have been recognized for many years as one of the most important factors influencing the magnitude of the diuretic response to organic mercurials. Diuresis is potentiated during metabolic acidosis and is suppressed during metabolic alkalosis. The mechanism by which these effects are mediated has been the subject of a number of studies. In general, two separate points of view have been considered: first, that they are attributable to changes in $\mathrm{pH}$ which presumably either modify the metabolic fate of the mercurial $^{4}$ or alter the affinity of a renal component for the drug; and secondly, that the responsiveness of the kidney varies with alterations in the ionic composition of the plasma which are independent of $\mathrm{pH}$. Evidence in support of the latter thesis has been presented by Axelrod and Pitts (1) in studies on respiratory and metabolic acidosis. These authors have postulated that the concentration of chloride in the glomerular filtrate is the major factor that determines the effect of organic mercurials. Although this thesis has been widely accepted in recent years, there are a number of observations which cannot be explained by

\footnotetext{
1 Supported by National Science Foundation Grant NSF-G 2113 and by a gift from the Smith, Kline and French Co. A preliminary report of some of these studies has been published in "Mechanism of Action of Mercurial and Xanthine Diuretics" which appeared in Chlorothiazide and Other Diuretic Agents, Ann. N. Y. Acad. Sci., vol. 71, article 4. Figures 1 and 2 of the present article are reproduced with permission of The New York Academy of Sciences.

2 Fellow of the National Foundation for Infantile Paralysis. Present address: Sinai Hospital, Baltimore 5, Md.

${ }^{3}$ Postdoctoral Fellow of the National Science Foundation.

4 The older literature speaks of the "dissociation of mercurials" under the influence of acids. The process really involves the rupture of a covalent carbon-mercury bond which is not an ionic dissociation in the usual sense.
}

it. These include the diuretic response observed during ammonium nitrate acidosis (2), chronic ammonia chloride administration (3), and the extracellular alkalosis of potassium depletion (4).

Experiments were therefore designed to reexamine the hypothesis that $\mathrm{pH}$ itself might influence the metabolic fate of organic mercurials. Benesch and Benesch have described a two step reaction between mersalyl and dimercaprol (5). The first reaction results in the formation of a dimercaptide and is not $\mathrm{pH}$ dependent; the second reaction results in the rupture of a carbon to mercury bond and is $\mathrm{pH}$ dependent. Using this in vitro reaction as a model, it was decided to compare the diuretic response to an organic mercurial with that to inorganic mercury under different conditions of acid-base balance. Thus, it was postulated that inorganic mercury, not requiring the rupture of the carbon to mercury bond, might be effective during acute metabolic alkalosis, whereas an organic mercurial would be relatively ineffective.

\section{METHODS}

Two types of experiments were carried out on trained mongrel female dogs. In one type standard clearance techniques were employed with continuous intravenous infusion, while in the other metabolism cages were used for collecting urine for three hours after drug administration. Since the clearance studies lasted for a similar three hours, the results obtained from these two types of studies have been combined where applicable. Each dog served as her own control, with an interval of at least one week between experiments. Dogs were maintained on a standard diet consisting of Purina Chow Dog Checkers.

In the clearance experiments, animals were fasted 12 to 18 hours before each experiment, but allowed free access to water. Alkalosis was produced by the rapid infusion of 300 to $500 \mathrm{ml}$. of isotonic sodium bicarbonate at $14 \mathrm{ml}$. per minute until the urine became alkaline and the plasma bicarbonate was elevated to the range of 26 
TABLE I

Comparison of meralluride and mercuric-cysteine in metabolic alkalosis, metabolic acidosis and under normal conditions*

\begin{tabular}{|c|c|c|c|c|c|c|c|c|}
\hline \multirow[b]{2}{*}{ Condition } & \multirow[b]{2}{*}{ Drugt } & \multirow[b]{2}{*}{$\mathrm{C}_{\mathbf{c r}}$} & \multicolumn{4}{|c|}{ Plasma } & \multirow[b]{2}{*}{$\Delta \mathrm{UCl}_{\mathrm{cl}} \ddagger$} & \multirow{2}{*}{$\begin{array}{c}\text { Peak } \\
\Delta U_{\text {clV }} \$ .8\end{array}$} \\
\hline & & & $\mathrm{Na}$ & $\mathbf{K}$ & $\mathrm{HCO}_{2}$ & $\mathrm{Cl}$ & & \\
\hline \multicolumn{2}{|c|}{ Dog: Biggy, $30 \mathrm{Kg}$. } & $\operatorname{ml} . / \min$ & \multicolumn{3}{|c|}{$m E q . / L$} & \multicolumn{2}{|r|}{$m E q . / 3 \mathrm{hr}$} & $\mu E q . / \min$. \\
\hline $\begin{array}{l}\text { Alkalosis } \\
\text { Alkalosis } \\
\text { Normal } \\
\text { Normal }\end{array}$ & $\begin{array}{l}\text { Meralluride } \\
\text { Mercuric chloride } \\
\text { Meralluride } \\
\text { Mercuric chloride }\end{array}$ & $\begin{array}{l}101 \\
105 \\
109 \\
166\end{array}$ & & & $\begin{array}{l}30.2 \\
31.6 \\
22.2 \\
21.4\end{array}$ & $\begin{array}{r}104 \\
99 \\
109 \\
110\end{array}$ & $\begin{array}{l}-3 \pi \\
+70 \pi \\
+58^{* *} \\
+97\end{array}$ & $\begin{array}{l}+\quad 29 \\
+\quad 965 \\
+\quad 923 \\
+1,104\end{array}$ \\
\hline \multicolumn{9}{|c|}{ Dog: Teddy, $19 \mathrm{Kg}$. } \\
\hline $\begin{array}{l}\text { Alkalosis } \\
\text { Alkalosis } \\
\text { Normal } \\
\text { Normal } \\
\text { Acidosis } \\
\text { Acidosis }\end{array}$ & $\begin{array}{l}\text { Meralluride } \\
\text { Mercuric-cysteine } \\
\text { Meralluride } \\
\text { Mercuric-cysteine } \\
\text { Meralluride } \\
\text { Mercuric-cysteine }\end{array}$ & $\begin{array}{l}70 \\
53 \\
62 \\
61 \\
74 \\
55\end{array}$ & $\begin{array}{l}150 \\
155 \\
156 \\
145\end{array}$ & $\begin{array}{l}2.7 \\
3.4 \\
3.4 \\
4.0\end{array}$ & $\begin{array}{l}26.0 \\
26.8 \\
21.4 \\
21.7 \\
15.2 \\
17.7\end{array}$ & $\begin{array}{l}104(-5.2) \\
103(-6.0) \\
111 \\
113 \\
117 \\
116\end{array}$ & $\begin{array}{l}-\quad 0.4 \\
+85 \\
+71 \\
+151 \\
+127 \\
+172\end{array}$ & $\begin{array}{l}+182 \\
+\quad 747 \\
+\quad 863 \\
+1,570 \\
+1,468 \\
+1,522\end{array}$ \\
\hline \multicolumn{9}{|c|}{ Dog: Mischief, $20 \mathrm{Kg}$. } \\
\hline $\begin{array}{l}\text { Alkalosis } \\
\text { Alkalosis } \\
\text { Normal } \\
\text { Normal } \\
\text { Acidosis } \\
\text { Acidosis }\end{array}$ & $\begin{array}{l}\text { Meralluride } \\
\text { Mercuric-cysteine } \\
\text { Meralluride } \\
\text { Mercuric-cysteine } \\
\text { Meralluride } \\
\text { Mercuric-cysteine }\end{array}$ & $\begin{array}{l}52 \\
75 \\
62 \\
77 \\
88 \\
77\end{array}$ & $\begin{array}{l}154 \\
157 \\
155 \\
147 \\
151 \\
146\end{array}$ & $\begin{array}{l}3.4 \\
3.4 \\
3.2 \\
3.2 \\
3.4 \\
3.6\end{array}$ & $\begin{array}{l}29.2 \\
26.8 \\
21.9 \\
22.8 \\
18.4 \\
17.3\end{array}$ & $\begin{array}{l}105(-5.0) \\
112(-6.0) \\
109 \\
108 \\
113 \\
119\end{array}$ & $\begin{array}{l}+16 \\
+51 \\
+24 \pi \\
+109 \\
+88 \\
+112\end{array}$ & $\begin{array}{l}+146 \\
+\quad 634 \\
+\quad 485 \\
+1,222 \\
+1,059 \\
+1,078\end{array}$ \\
\hline \multicolumn{9}{|c|}{ Dog: Satin, 20-23 Kg. } \\
\hline $\begin{array}{l}\text { Alkalosis } \\
\text { Alkalosis } \\
\text { Normal } \\
\text { Normal } \\
\text { Acidosis } \\
\text { Acidosis }\end{array}$ & $\begin{array}{l}\text { Meralluride } \\
\text { Mercuric-cysteine } \\
\text { Meralluride } \\
\text { Mercuric-cysteine } \\
\text { Meralluride } \\
\text { Mercuric-cysteine }\end{array}$ & $\begin{array}{l}72 \\
64 \\
69 \\
64 \\
95 \\
83\end{array}$ & $\begin{array}{l}149 \\
154 \\
152 \\
148 \\
145 \\
146\end{array}$ & $\begin{array}{l}3.0 \\
3.4 \\
3.7 \\
4.0 \\
4.7 \\
3.8\end{array}$ & $\begin{array}{l}27.3 \\
28.0 \\
19.6 \\
19.0 \\
14.9 \\
15.6\end{array}$ & $\begin{array}{l}104(-5.0) \\
106(-7.0) \\
114 \\
115 \\
121 \\
119\end{array}$ & $\begin{array}{l}+13 \\
+56 \\
+83 \\
+181 \\
+255 \\
+255\end{array}$ & $\begin{array}{r}+153 \\
+\quad 681 \\
+\quad 772 \\
+1,674 \\
+2,425 \\
+2,182\end{array}$ \\
\hline
\end{tabular}

* Values for plasma electrolytes and for creatinine clearance $\left(\mathrm{C}_{\mathrm{Cr}_{\mathrm{r}}}\right)$ are averages of periods before and for 40 minutes after administration of mercurial. luride.

† Drugs were administered in a dose of $1 \mathrm{mg}$. of $\mathrm{Hg}$ per $\mathrm{Kg}$. for mercuric salts, and $2 \mathrm{mg}$. of $\mathrm{Hg}$ per $\mathrm{Kg}$. for meral-

$\ddagger \triangle \mathrm{U}_{\mathrm{Cl}} \mathrm{V}$ represents the chloride excretion in excess of control excretion for the duration of the experiment.

The values in this column indicate the peak rate of chloride excretion above control levels.

|| Figures in parentheses opposite values for plasma chloride refer to change in chloride concentration (mEq. per L.), resulting from bicarbonate infusion.

I 140 minutes.

** 100 minutes.

to $29 \mathrm{mEq}$. per L. In experiments during normal conditions of acid-base balance $300 \mathrm{ml}$. of isotonic sodium chloride was infused, and serum chloride and bicarbonate remained within the normal range. Acidosis was produced by the administration of 10 grams of ammonium chloride by stomach tube in two divided doses on the afternoon prior to the experiment. During the clearance experiment itself, the acidotic dog received the same priming and sustaining infusion as in the experiments carried out under normal conditions. In all experiments following completion of the initial infusion, the rate was reduced to $2 \mathrm{ml}$. per minute using a solution identical in electrolyte concentration to that initially employed. Creatinine was added to all infusions to maintain constant plasma levels of about $20 \mathrm{mg}$. per cent. Thirty minutes were allowed for equilibration and two $20 \mathrm{~min}$ ute control periods were then taken. The diuretic was injected intravenously over a five minute period. Meral- luride, $52 \mathrm{mg}$. of mercury per $\mathrm{Kg}$., was used as the standard organic mercurial. Inorganic mercury was administered as $1 \mathrm{mg}$. of mercury per $\mathrm{Kg}$. in the form of mercuric chloride in the early experiments. Later this was given with a tenfold excess of cysteine, mixed just prior to injection. This mixture is referred to as mercuric cysteine. All dogs receiving this agent were treated with dimercaprol for the subsequent two to three days.

In the "cage" experiments, fasted dogs were catheterized in the morning, returned to their cages, and were permitted no further food or water. At the end of two hours, a control collection of urine was obtained by catheterization, following which the mercurial was administered slowly intravenously. The urine was collected

${ }^{5}$ Generously supplied by Drs. H. L. Daiell and H. L. Friedman, Lakeside Laboratories, Inc., Milwaukee 1, Wisc. 
for the next three hours, at the end of which the bladder was emptied by catheterization. In control experiments, without diuretics, electrolyte excretions were essentially constant during this five hour period. In both the "clearance" and "cage" types of experiments, results have been expressed in most instances as the change in urinary chloride excretion, obtained by subtracting the control rate of excretion from that after the diuretic.

The creatinine clearance $\left(\mathrm{C}_{\mathrm{or}_{r}}\right)$ was used as the measure of the glomerular filtration rate; creatinine was determined by the alkaline picrate method using trichloroacetic acid filtrates of plasma. Sodium and potassium were determined on a Patwin flame photometer with an internal lithium standard; plasma carbon dioxide was determined on samples collected anaerobically by the manometric method of Van Slyke; urine carbon dioxide, by the volumetric method of Van Slyke. In all experiments, results have been expressed as the concentration of bicarbonate $\left(\mathrm{HCO}_{3}^{-}\right)$in the plasma, obtained, by subtracting carbonic acid from total $\mathrm{CO}_{2}$. In some experiments, when $\mathrm{pH}$ was determined, carbonic acid was calculated from the Henderson-Hasselbalch equation; in others, $\mathrm{pCO}_{2}$ was assumed constant at $40 \mathrm{~mm}$. $\mathrm{Hg}$. Urine and blood samples were collected anaerobically under oil and $\mathrm{pH}$ was determined immediately with a Beckman Model $\mathrm{G}$ pH meter. Chloride was originally measured by the method of Wilson and Ball (6) and in later experiments by the electrometric titration method of Cotlove (7).

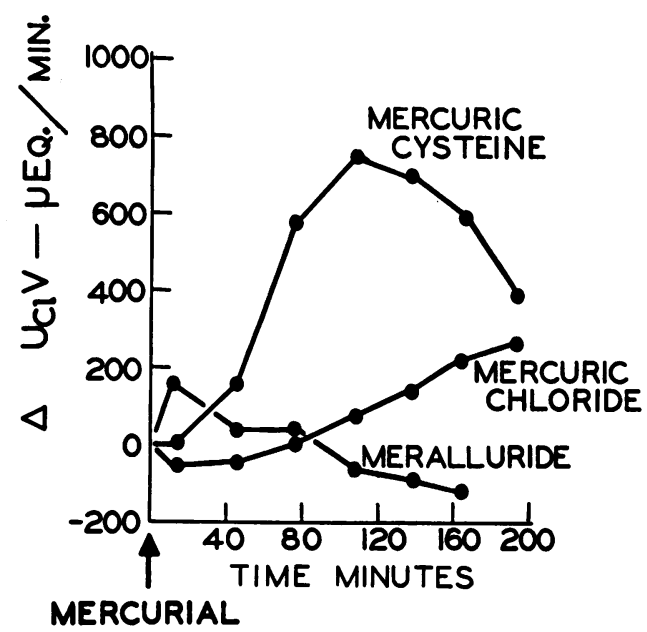

Fig. 1. Chloride Excretion in Response to Three Different Forms OF MERCuRy in aN Alkalotic Dog

The data are from experiments on the same dog (weight, $19 \mathrm{Kg}$.). The amount of bicarbonate infused and the plasma electrolyte concentrations were essentially the same in each experiment. The ordinate is a measure of the change in the rate of chloride excretion relative to premercury periods. The dose of meralluride was $2 \mathrm{mg}$. of $\mathrm{Hg}$ per $\mathrm{Kg}$.; of $\mathrm{HgCl}_{2}$ and $\mathrm{Hg}$ cysteine, $1 \mathrm{mg}$. of $\mathrm{Hg}$ per Kg.

\section{RESULTS}

In preliminary experiments on acute metabolic alkalosis comparison was made between the effects of meralluride $(2 \mathrm{mg}$. of $\mathrm{Hg}$ per $\mathrm{Kg}$.) and inorganic mercury as mercuric chloride $(1 \mathrm{mg}$. of $\mathrm{Hg}$ per $\mathrm{Kg}$.). In confirmation of many previous observations the organic mercurial was ineffective. In contrast, mercuric chloride had a marked chloruretic action in some dogs, while in others this was less marked and appeared late in the experiment (see Table I and Figure 1). It was considered that this inconsistent response might be related either to cardiac toxicity or to binding of mercuric ions to plasma proteins and to early distribution to organs other than the kidney. Since Farah and Maresh (8) have shown that the administration of a monothiol, such as cysteine, reduces cardiac toxicity without alteration in diuretic potency, inorganic mercury was administered as mercuric cysteine in subsequent experiments. As shown in Table I and Figure 1, mercuric cysteine uniformly produced a chloruresis during alkalosis.

Since the acute metabolic acidosis produced by ammonium chloride potentiates the chloruretic action of organic mercurials, experiments were undertaken to determine whether the action of inorganic mercury (as mercury cysteine) would be similarly increased. Table I summarizes the results in three dogs. Under normal conditions meralluride produced an average increase in chloride excretion of $2.9 \mathrm{mEq}$. per $\mathrm{Kg}$. over a three hour period. With ammonium chloride acidosis, this value increased to $7.4 \mathrm{mEq}$. per $\mathrm{Kg}$. With mercuric cysteine, there was little potentiation with acidosis, the average values being $7.1 \mathrm{mEq}$. per $\mathrm{Kg}$. for normal and $8.6 \mathrm{mEq}$. per $\mathrm{Kg}$. for acidosis.

In the above experiments, mercuric cysteine and meralluride were administered in the arbitrary doses of 1 and $2 \mathrm{mg}$. of $\mathrm{Hg}$ per $\mathrm{Kg}$., respectively. While the greater potency of mercuric cysteine during alkalosis was consistent with the initial hypothesis, it was not anticipated that mercuric cysteine would be a more potent diuretic than the organic mercurial under conditions of normal acidbase balance. Previous observations have indicated that organic mercurials are much more effective diuretics than inorganic mercury. Indeed, the relative potency of the organic and inorganic 


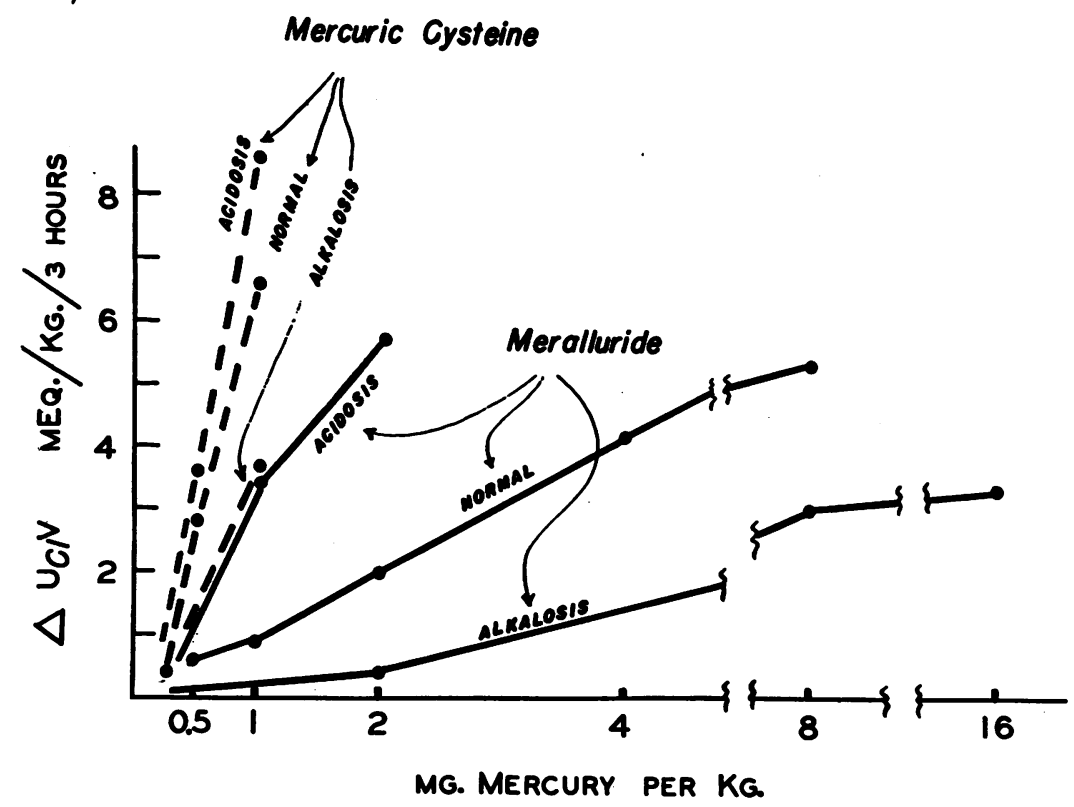

Fig. 2. The Effect of Actd-Base Balance on Chloruretic Response to Meralluride and Mercuric Cysteine

Each point represents the mean of three or more experiments. Plasma bicarbonate levels for alkalotic dogs fell between 26 to $30 \mathrm{mEq}$. per L.; for normal dogs, between 19 to $25 \mathrm{mEq}$. per L.; and for acidotic dogs, between 15 to 18 $\mathrm{mEq}$. per L. This figure includes all applicable data from "cage" and "clearance" experiments.

forms of mercury has been considered as evidence that the organic compounds act as intact molecules rather than by the rupture of a carbon to mercury bond (9). Experiments were therefore done to compare mercuric cysteine and meralluride over a wide dosage range. As shown in Figure 2, the maximal increase in chloride excretion was about $8 \mathrm{mEq}$. per $\mathrm{Kg}$. over the three hour period of observation. This corresponds to the loss of approximately one-third of the chloride in extracellular fluid, and is also equivalent to the excretion of approximately 20 per cent of the filtered chloride at the peak of the diuretic response.

Several points of interest are to be emphasized from the data depicted in Figure 2:1) Mercuric cysteine, at $1 \mathrm{mg}$. of $\mathrm{Hg}$ per $\mathrm{Kg}$., produced the maximal response. Larger doses were not administered because of the possibility of late toxicity. 2) During alkalosis, the chloruresis due to mercuric cysteine is about one-half the maximal response. 3) During acidosis, meralluride was potentiated to such an extent that it became almost as effective as mercuric cysteine. However, mercuric cysteine was not significantly potentiated by acidosis. 4) Under normal conditions and during alkalosis, meralluride was much less potent than the inorganic form of mercury. 5) While meralluride at $2 \mathrm{mg}$. of $\mathrm{Hg}$ per $\mathrm{Kg}$. is virtually inactive during alkalosis, moderate chloruresis is obtained if the dose is greatly increased ( 8 or $16 \mathrm{mg}$. of $\mathrm{Hg}$ per $\mathrm{Kg}$.). On the basis of reaction kinetics, this finding would be anticipated if diuretic activity depended on a $\mathrm{pH}$ dependent reaction involving the organic mercurial. Estimation of the relative potencies of these agents is as follows: During acidosis, $0.5 \mathrm{mg}$. of $\mathrm{Hg}$ of mercuric cysteine is equivalent to about $1 \mathrm{mg}$. of $\mathrm{Hg}$ of meralluride (ratio, $1: 2$ ). Under normal conditions, 0.5 $\mathrm{mg}$. of $\mathrm{Hg}$ of mercuric cysteine is equivalent to about $3.5 \mathrm{mg}$. of $\mathrm{Hg}$ of meralluride (ratio, $1: 7$ ). During alkalosis, $1 \mathrm{mg}$. of $\mathrm{Hg}$ of mercuric cysteine is equivalent to about $16 \mathrm{mg}$. of $\mathrm{Hg}$ of meralluride (ratio, 1:16). It is obvious, therefore, that the organic mercurial is a relatively weak diuretic and that it approaches the potency of inorganic mercury only under acidotic conditions.

Comparison was also made of mercuric cysteine and chlormerodrin (Neohydrin ${ }^{\otimes}$ ), which was se- 
lected because of reports indicating that it is more potent than meralluride (10). Under normal conditions, an approximately equivalent response was obtained with $0.5 \mathrm{mg}$. of $\mathrm{Hg}$ per $\mathrm{Kg}$. as mercuric cysteine, $1.0 \mathrm{mg}$. of $\mathrm{Hg}$ per $\mathrm{Kg}$. as chlormerodrin, and $3.5 \mathrm{mg}$. of $\mathrm{Hg}$ per $\mathrm{Kg}$. as meralluride. In addition, during alkalosis, chlormerodrin $(2 \mathrm{mg}$. of $\mathrm{Hg}$ per $\mathrm{Kg}$.) resembled meralluride in that it failed to produce a chloruresis.

The magnitude of diuresis has been considered in terms of the urinary excretion of chloride since the primary effect of mercurials is generally believed to be chloruretic (1). In all experiments, changes in urinary sodium paralleled those of chloride; variations in potassium excretion were minor and inconsistent. In some experiments, an increase in bicarbonate excretion was noted; this was related to slight fluctuations in the serum bicarbonate concentration.

In the present experiments the peak response was obtained between one and two hours and, by the third hour, the diuresis had subsided. As shown in Table I, the same relationships were observed whether the results were expressed as the change in chloride excretion over this entire period or as the peak rate of excretion. Others have shown that the absolute magnitude of chloruresis is partially determined by the volume of extracellular fluid (11).

Although it has been shown that an acute reduction in filtration rate to 75 per cent of the control value blocks the response to organic mercurials (12), it is apparent from the results shown in Table I that comparable spontaneous day to day variations in the filtration rate have no observable effect on diuresis. Although multiple doses of mercurials were administered, no significant changes in filtration rate were observed over an extended period of time, and, in individual experiments, there were no consistent changes immediately after the administration of either drug.

Since the acute production of either metabolic acidosis or metabolic alkalosis involves changes in plasma chloride concentration as well as in $\mathrm{pH}$, an experiment was undertaken in an attempt to modify acid-base balance while keeping plasma chloride level essentially constant. This was accomplished by adding to an infusion of sodium chloride a fixed amount of other sodium salts, either bicarbonate, nitrate or sulfate. The results obtained in two dogs are shown in Table II and Figure 3. In all experiments either a normal or

TABLE II

Effect of meralluride in dog loaded with sodium chloride in combination with another sodium salt*

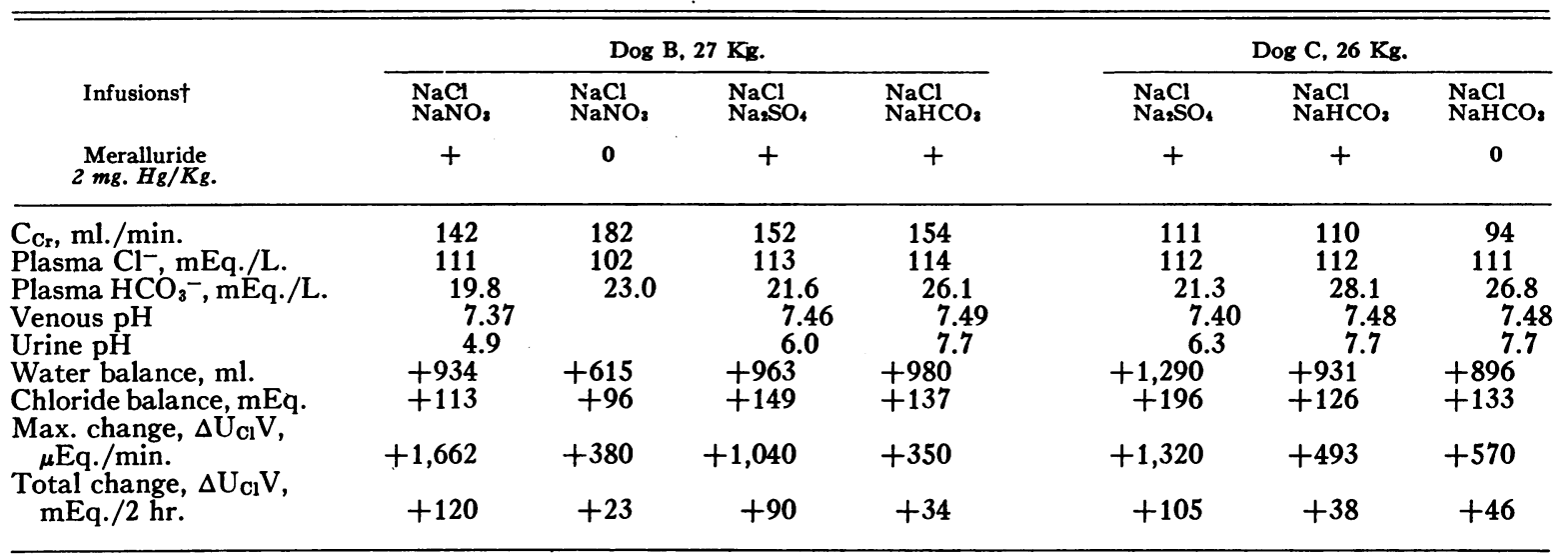

* Values given for creatinine clearance $\left(\mathrm{C}_{\mathrm{C}_{r}}\right)$, plasma electrolytes, and plasma and urine $\mathrm{pH}$ are the average for two 20 minute periods before and two 20 minute periods after mercurial administration. Water and chloride balance represent the difference between total input and output at the time of drug administration. In all experiments, the control rate of chloride excretion was calculated for the 40 minutes before mercurial or a corresponding period when no drug was given. In the control experiments (without mercurials) the change in $U_{\mathrm{Cl}} \mathrm{V}$ was calculated for an interval of time corresponding exactly to the postmercurial period. In all experiments the plasma chloride level at the time of mercurial administration was 0 to $3 \mathrm{mEq}$. per $\mathrm{L}$. higher than the preinfusion value.

† Dogs were loaded with $1 \mathrm{~L}$. of a primary intravenous infusion containing $150 \mathrm{mEq}$. of $\mathrm{NaCl}, 25 \mathrm{mEq}$. of $\mathrm{NaHCO}_{3}$, and $125 \mathrm{mEq}$. of the test salt; infusion time, 50 to 60 minutes. The sustaining infusion at about $10 \mathrm{ml}$. per minute contained $115 \mathrm{mEq}$. per L. of $\mathrm{NaCl}$ and $60 \mathrm{mEq}$. per L. of test salt. Meralluride was administered 70 minutes after the start of the sustaining infusion. 


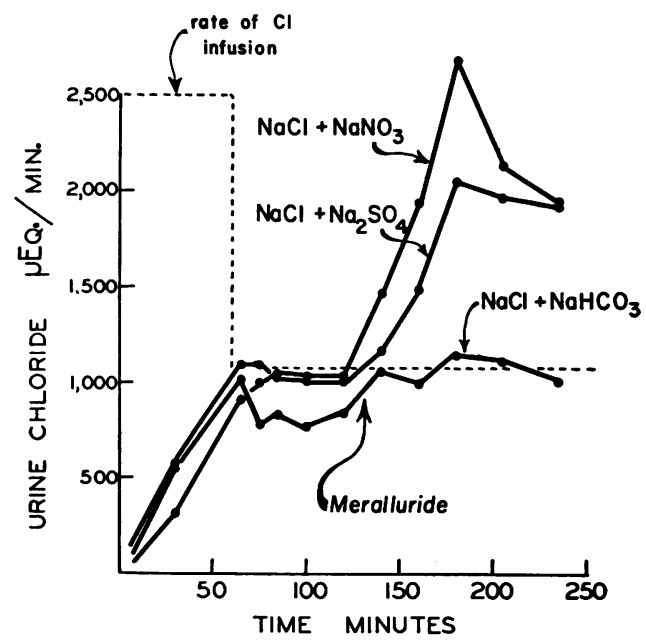

Fig. 3. The Effect of the Infusion of Chloride Plus Another Anion on the Chloruretic Response to Meralluride

The dotted line represents the average rate of primary and sustaining chloride infusions which varied not more than 10 per cent from one experiment to the other. The protocol for these experiments and the clearance and plasma electrolyte data are summarized in Table II (Dog B).

an increased chloride load was delivered to the tubules. Under these conditions the alkalosis produced in the sodium bicarbonate experiments was associated with a slight elevation of the serum chloride. This alkalosis was accompanied by a marked decrease in the chloruretic response to meralluride; a normal chloruresis was obtained when the additional anion load was either nitrate or sulfate.

\section{DISCUSSION}

The present evidence relating to the effect of acid-base balance on mercurial action may be summarized as follows. Consistent with the "chloride load hypothesis" are the following: 1) In the comparison of respiratory and metabolic acidosis, potentiation of mercurial diuresis is correlated with hyperchloremia rather than with the $\mathrm{pH}$ of the plasma (1). ${ }^{6}$ 2) Although mercuric cysteine

6 There is no a priori reason why plasma $\mathrm{pH}$ must be implicated in the action of mercurials. The $\mathrm{pH}$ at the intra-renal site of action of the drug is probably the critical parameter, and there is no evidence to suggest the changes there will be the same as in plasma. The acidity of urine is a parameter that correlates well with mercurial effectiveness (see below). is not significantly potentiated by ammonium chloride acidosis, its action is somewhat decreased by a moderate metabolic alkalosis with plasma bicarbonate levels in the range of 26 to $29 \mathrm{mEq}$. per $\mathrm{L}$. 3 ) An acute depression of the glomerular filtration rate is associated with a corresponding decrease in the amount of chloride filtered without any accompanying change in the $\mathrm{pH}$ of body fluids. While mercurials become inactive under these circumstances, the physiological disturbances are of such a nature that this type of experiment may well not be relevant to the present problem.

The following observations cannot be readily interpreted in terms of the "chloride load hypothesis": 1) Metabolic alkalosis and acidosis have a profound effect on the potency of organic mercurials and considerably less of an effect on the potency of inorganic mercury given as the mercuric cysteine complex. 2) The simultaneous administration of acetazolamide inhibits organic mercurials (13) but our preliminary experiments indicate only a negligible effect on mercuric cysteine. 3) When various sodium salts are administered along with sodium chloride, the chloruretic response to organic mercurials is inhibited during metabolic alkalosis despite slight elevations in the plasma chloride level. 4) In the dog, a decrease in plasma chloride of 5 to $7 \mathrm{mEq}$. per L. is uniformly associated with refractoriness to organic mercurials when this is produced by isotonic sodium bicarbonate infusions, but a normal mercurial diuresis is obtained if a similar degree of hypochloremia is produced by simple hemodilution, i.e., by the administration of water (14). ${ }^{7}$ 5) During potassium depletion there is a normal response to mercurials despite hypochloremia (4). 6) Ammonium nitrate potentiates mercurial diuresis without an increase in plasma chloride (2). 7) Potentiation of mercurials by ammonium chloride occurs in chronic experiments in the absence of hyperchloremia (3).

If the diuretic action of mercurials involves a $\mathrm{pH}$ dependent reaction, does this occur in the cells of the kidney or in the urine within the tubule? Our knowledge of renal intracellular $\mathrm{pH}$ is so

7 A similar observation has been reported by Farah and Koda (15) who obtained a chloruretic response to mercurials following reduction of plasma chloride to values as low as $80 \mathrm{mEq}$. per $\mathrm{L}$. by the administration of hypotonic solutions. 
fragmentary and so indirect that this question cannot be answered at present. Since the electrolyte metabolism of the kidney is so different from that of other tissues, it would appear unreasonable to attempt to define renal mechanisms by extrapolation from other tissues. It is generally believed that the site of mercurial action is on the tubular cell (or on its membrane), and there is good evidence that mercurials are taken up by the cells of the kidney and thence secreted into the tubular urine (16-18). Hence it might be logical to conceive of a $\mathrm{pH}$ dependent reaction as occurring within the cell itself. However, there is no a priori reason why the rupture of a carbon to mercury bond could not occur within the tubular urine. This might then be followed by a subsequent reaction between mercuric ions and the immediately adjacent cellular membrane. In this connection the findings reported by Nicholson (19) are of interest. He employed a histochemical modification of the earlier experiment of Macallum and Campbell (20) and interpreted his findings as indicating a zone of marked acidity in the region of the brush border of the proximal tubule.

Mercuric cysteine was initially employed in these experiments because of the possibility that the inconsistent results obtained with mercuric chloride might be attributable to cardiac toxicity. In retrospect no evidence of cardiac toxicity was observed with mercuric chloride when given slowly intravenously in the small doses that were employed. A more plausible interpretation of the relative potencies of mercuric chloride and mercuric cysteine involves their distribution within the body. Tissue analyses have not been performed. However, it was observed that the initial rate of excretion of mercury in the urine was about twice as great with mercuric cysteine as with mercuric chloride (21); presumably this may be a function of the amount taken up by the kidney from the plasma.

The relative ineffectiveness of mercuric chloride, when compared to organic mercurials, has previously been considered as evidence against the thesis that the diuretic activity of the organic compounds is attributable to the mercuric ion itself (9). However, the argument loses validity by the demonstration that the mercuric cysteine complex is more potent than the organic mercurials thus far tested. Further evaluation of this question involves a consideration of the metabolism and structure-activity relationships of the organic compounds. Our findings, to be presented in a subsequent paper, support the thesis that diuretic activity results from the rupture of a carbon to mercury bond with the liberation of mercuric ions.

\section{SUMMARY}

The potentiation of mercurial diuretics by acidforming salts was studied by two approaches. First, the effects of varying doses of meralluride and a mercuric salt, mercuric cysteine, on chloruresis were compared in normal, acidotic $\left(\mathrm{NH}_{4} \mathrm{Cl}\right)$ and alkalotic $\left(\mathrm{NaHCO}_{3}\right)$ dogs. The mercuric salt is a much more potent chloruretic and it is influenced to a much smaller extent by changes in acid-base balance than is meralluride. This finding is interpreted as indicating that a major part of potentiation by acid-forming salts is related to the relative ease of release of mercuric ions from organic mercurials in acid media.

Second, dogs received hypertonic infusions which kept plasma chloride concentration and glomerular filtration rate elevated, while the acidbase balance was varied by the infusion of other anions, i.e., nitrate, sulfate and bicarbonate. Under these circumstances, with almost identical chloride load, bicarbonate inhibited the mercurial effect, while nitrate and sulfate did not. This finding emphasizes the role of $\mathrm{pH}$ in determining mercurial effectiveness.

\section{REFERENCES}

1. Axelrod, D. R., and Pitts, R. F. The relationship of plasma $\mathrm{pH}$ and anion pattern to mercurial diuresis. J. clin. Invest. 1952, 31, 171.

2. Ethridge, C. B., Myers, D. W., and Fulton, M. N. Modifying effect of various inorganic salts on the diuretic action of salyrgan. Arch. intern. Med. 1936, 57, 714.

3. Hilton, J. G. Potentiation of diuretic action of mercuhydrin by ammonium chloride. $\mathrm{J}$. clin. Invest. 1951, 30, 1105.

4. Mudge, G. H., and Hardin, B. Response to mercurial diuretics during alkalosis: A comparison of acute metabolic and chronic hypokalemic alkalosis in the dog. J. clin. Invest. 1956, 35, 155.

5. Benesch, R., and Benesch, R. E. Reactions of thiols with organic mercury compounds. Arch. Biochem. 1952, 38, 425. 
6. Wilson, D. W., and Ball, E. G. A study of the estimation of chloride in blood and serum. J. biol. Chem. 1928, 79, 221.

7. Cotlove, E., Trantham, H. V., and Bowman, R. L. An instrument and method for automatic, rapid, accurate, and sensitive titration of chloride in biologic samples. J. Lab. clin. Med. 1958, 51, 461.

8. Farah, A., and Maresh, G. Influence of sulfhydryl compounds on diuresis and renal and cardiac circulatory changes caused by mersalyl. J. Pharmacol. exp. Ther. 1948, 92, 73.

9. Kessler, R. H., Lozano, R., and Pitts, R. F. Studies on structure diuretic activity relationships of organic compounds of mercury. J. clin. Invest. 1957, 36, 656.

10. Handley, C. A., Chapman, D., and Moyer, J. H. Some pharmacological properties of three new mercurial diuretics. Proc. Soc. exp. Biol. (N. Y.) 1951, 78, 433.

11. Duggan, J. J., and Pitts, R. F. Studies on diuretics. I. The site of action of mercurial diuretics. J. clin. Invest. 1950, 29, 365.

12. Pitts, R. F., and Duggan, J. J. Studies on diuretics. II. The relationship between glomerular filtration rate, proximal tubular absorption of sodium and diuretic efficacy of mercurials. J. clin. Invest. 1950, 29, 372 .
13. Maren, T. H. Combined action of a mercurial and a carbonic anhydrase inhibitor on renal sodium excretion in dogs. Fed. Proc. 1955, 14, 366.

14. Mudge, G. H., Ames, A., III, Foulks, J., and Gilman, A. Effect of drugs on renal secretion of potassium in the dog. Amer. J. Physiol. 1950, 161, 151.

15. Farah, A., and Koda, F. The influence of plasma electrolyte concentration on mercurial diuresis in the dog. J. Pharmacol. exp. Ther. 1954, 110, 361.

16. Weston, R. E., Grossman, J., Lehman, R. A., Ullmann, T. D., Halpern, J. P., and Leiter, L. Renal extraction and excretion of mercury in man following intravenously administered mercurial diuretics. J. clin. Invest. 1951, 30, 1221.

17. Borghgraef, R. R. M., and Pitts, R. F. The distribution of chlormerodrin (Neohydrin(\$) in tissues of the rat and dog. J. clin. Invest. 1956, 35, 31.

18. Weiner, I. M., Burnett, A. E., and Rennick, B. R. The renal tubular secretion of mersalyl (salyrgan) in the chicken. J. Pharmacol. exp. Ther. 1956, $118,470$.

19. Nicholson, T. F. Site of acidification in the dog's kidney. Fed. Proc. 1954, 13, 269.

20. Macallum, A. B., and Campbell, W. R. The secretion of "acid" by the kidney. Amer. J. Physiol. 1929, 90, 439.

21. Weiner, I. M., Levy, R. I., and Mudge, G. H. In preparation. 